\section{Marcia Simões-Zenari}

Mariangela Lopes Bitar

Nair Katia Nemr
Departamento de Fisioterapia, Fonoaudiologia e Terapia Ocupacional. Faculdade de Medicina. Universidade de São Paulo. São Paulo, SP, Brasil

\section{Correspondence:}

Marcia Simões-Zenari

R. Prof. Wlademir Pereira, 61 - Casa 3

Vila São Francisco

05386-360 São Paulo, SP, Brasil

E-mail:marciasz@usp.br

Received: 11/9/2011

Approved: 1/30/2012

Article available from: www.scielo.br/rsp

\section{The effect of noise on the voice of preschool institution educators}

\begin{abstract}
OBJECTIVE: To analyze the association between noise levels present in preschool institutions and vocal disorders among educators.

METHODS: Cross-sectional study conducted in 2009 with 28 teachers from three preschool institutions located in the city of São Paulo (Southeastern Brazil). Sound pressure levels were measured according to Brazilian Technical Standards Association, with the use of a sound level meter. The averages were classified according to the levels of comfort, discomfort, and auditory damage proposed by the Pan American Health Organization. The educators underwent voice evaluation: self-assessment with visual analogue scale, auditory perceptual evaluation using the GRBAS scale, and acoustic analysis utilizing the Praat program. To analyze the association between noise and voice evaluation, descriptive statistics and the chi-square test were employed, with significance of $10 \%$ due to sample size.
\end{abstract}

RESULTS: The teachers' age ranged between 21 and 56 years. The noise average was $72.7 \mathrm{~dB}$, considered as damage 2 . The professionals' vocal self-assessment ranked an average of 5.1 on the scale, being considered as moderate alteration. In the auditory-perceptual assessment, $74 \%$ presented vocal alteration, especially hoarseness; of these, $52 \%$ were considered mild alterations. In the acoustic assessment the majority presented fundamental frequency below the expected level. Averages for jitter, shimmer and harmonic-noise ratio showed alterations. An association between the presence of noise between the harmonics and vocal disorders was observed.

CONCLUSIONS: There is an association between presence of noise between the harmonics and vocal alteration, with high noise levels. Although most teachers presented mild voice alteration, the self-evaluation showed moderate alteration, probably due to the difficulty in projection.

DESCRIPTORS: Caregivers. Voice Quality. Voice Disorders. Noise Effects. Noise, Occupational. Child Day Care Centers. Cross-Sectional Studies.

\section{INTRODUCTION}

The teacher's voice has been the focus of research that investigates, prevents or minimizes occupational risks, since this professional category presents higher frequency of vocal alterations than the population in general., ${ }^{2,6,24}$

It is necessary to implement actions that lead to the effective reduction in dysphonia within the teaching category, preferably during professional education. ${ }^{2,4,16,24}$

These actions should consider behavioral and health aspects, work environment and organization, in addition to questions of relationship with students, 
families and the institutions' management. It is necessary to move from the preventive and individual focus towards health promotion targeted at the collective dimension. ${ }^{10,16,23}$

Programs that only provide information have a limited effect, since it is not the mere prescription of guidelines that will lead the teacher to change his/her vocal behavior. ${ }^{3,9,15,19,20}$ The union between informative or indirect approaches and more direct approaches seems to be the tendency of current studies in the area, as both complement one another. ${ }^{7}$

A recent literature review ${ }^{24}$ about high prevalence of vocal alteration among teachers argues that the main risk factors are: more advanced age and more years working as teachers, female sex, psychoemotional alterations, stress, high number of students per classroom and excessive background noise.

The environment's high noise level, associated with the intense use of the voice, generates high vocal loading. It is considered an important public health problem also in leisure activities and on the streets. In schools, it interferes in the children's concentration and learning. ${ }^{18}$ The discomfort that is felt in its presence can be described as indisposition, irritability and stress and is not directly related to the level of exposure. ${ }^{22}$ Communication difficulties have also been described, as well as headaches, sleep alterations, dizziness, hearing loss and tinnitus. ${ }^{22}$ Individual and collective preventive measures regarding noise exposure are indicated. ${ }^{14}$

A Brazilian study with approximately 2,000 teachers found that half of them had complaints about high or unbearable noise levels at school, inside or outside the classroom and associated with worse voice-related quality of life. ${ }^{10} \mathrm{~A}$ literature review ${ }^{13}$ analyzed studies in which the average noise level in educational institutions exceeded $70 \mathrm{dBA}$, which has also been observed in Brazilian day-care centers. ${ }^{21}$ Averages between 70 $\mathrm{dBA}$ and $85 \mathrm{dBA}$ have been found in primary school classrooms in which the teachers presented many symptoms that were possibly associated with noise exposure, among them, dysphonia. ${ }^{22}$ The average of $75 \mathrm{dBA}$ has been found in Italian day-care centers, 20 dBA above the 50-55 dBA recommended for this kind of institution. ${ }^{3, a}$

Due to these conditions, the educators would need to constantly use the voice in very high intensities to overcome in 15-20 dBA the signal-to-noise ratio and be understood..$^{10,13, \mathrm{a}}$ Constant exposure to sound pressure levels of $70 \mathrm{dBA}$ or more is considered a permanent health risk situation, increasing wear of organism and risks of infarction, stroke and infections. ${ }^{\text {b }}$

Teachers complain about the difficulty in speaking loudly and being heard/understood in noisy environments. ${ }^{17}$ Speaking in the presence of high noise levels can lead to an increase in fundamental frequency and effort or vocal hyperfunction, mainly in non-trained speakers. ${ }^{3}$ In view of the fact that a large part of the teachers present restrictions in voice modulation and in vocal projection, ${ }^{7}$ the presence of high noise levels at schools becomes even more relevant.

The improvement in the acoustic conditions of classrooms would be one of the main aspects to be tackled in an intervention program for teachers' adequate vocal use. ${ }^{3}$ Furthermore, the program should approach vocal techniques and involve the use of individual amplification devices. To achieve this, it is necessary to have better knowledge of the interrelation between voice and noise.

This study aimed to analyze the association between noise levels in preschool institutions and the presence of vocal alterations among educators.

\section{METHODS}

Cross-sectional observational study carried out at three preschool institutions in the city of São Paulo (Southeastern Brazil) in 2009. The institutions had established agreements with the Municipal Government, were managed by the same social institution and were located in the west zone of the city. They were selected by the criterion of convenience due to a partnership between the speech pathologists and the supporting institution for the development of health promotion actions. The 28 educators were invited to participate. Those who were absent or ill on the recording day would be excluded, but there were no losses.

The sound pressure levels were measured in the spaces of daily routine activities: classrooms, refectories, corridors, outdoor recreation areas, service areas and administrative rooms, in the presence and absence of the children.

A digital sound level meter of the brand Center, model 322, with Data Logger was used, and the norms of Associação Brasileira de Normas Técnicas (ABNT - Brazilian Technical Standards Association) ${ }^{\mathrm{c}}$ were followed. The device was calibrated and was operated in slow response curve in a sound level range between $30 \mathrm{dBA}$ and $130 \mathrm{~dB}$. The measurements were performed

a Acoustical Society of America. Classroom acoustics. New York; 2000

b World Health Organization. Résumé d'orientation des directives de I'OMS relatives au bruit dans l'environnement. Genève; 2003.

c Associação Brasileira de Normas Técnicas. Norma Brasileira NBR 10152 (NB-95): Níveis de ruído para conforto acústico. Rio de Janeiro; 2000. 
in the absence of atypical sound sources like rain or strong wind. Different points were considered in each measurement place, with a minimum time of five minutes per point, and measurement device in the fast operation mode. The measurement was performed in a central point in small spaces (up to $10 \mathrm{~m}^{2}$ ), two diagonal points were considered in medium spaces (larger than $10 \mathrm{~m}^{2}$ and up to $20 \mathrm{~m}^{2}$ ) and three points in large spaces (larger than 20 $\mathrm{m}^{2}$ ). The device was positioned heading to the center of the spaces at a distance of, at least, one meter above the floor and away from the walls or outside walls.

The minimum, medium and maximum values of the obtained sound pressure levels were considered and the means were classified according to what the World Health Organization recommends for comfort, discomfort and damage. ${ }^{b}$ The results were dichotomized into adequate (comfort)/altered (discomfort or damage).

The educators underwent voice evaluation: self-assessment, auditory-perceptual evaluation and acoustic evaluation of the voice.

A visual analogue scale was used with $10 \mathrm{~cm}$ of length for the vocal self-assessment, in which 0 (zero) represented absence of vocal alteration and 10, maximum vocal alteration. The educators should mark a vertical line representing the status of their voice in the last days. This line was subsequently measured with a ruler and the value was classified according to cut-off points per tertiles: no alteration (zero), mild alteration (values between 0.1 and 3.4), moderate alteration (values between 3.5 and 6.7) and extreme alteration (values between 6.8 and 10 ).

Voice samples of each educator were individually recorded: sustained emission of the vowel /a/ and counting numbers from 1 to 10 . This recording took place at the institutions, in distant and silent rooms, with maximum noise level of $50 \mathrm{~dB}$. The voices were recorded directly in a desktop computer and the acoustic analysis program Praat was used, together with a microphone of the make AKG.

The auditory-perceptual evaluation of the educators' vocal quality was performed using the GRBAS scale. ${ }^{8}$ Although this scale analyzes vocal quality only at the glottal level and is subjective, it was selected because it is utilized in studies across the world and because its application is simple and quick, as the educators would not be able to be absent from the classroom during a long period of time. The voices were analyzed by a speech pathologist who has been working in the area for more than ten years.

The educators were divided into three groups: adequate voice $(\mathrm{AVG})$ : $\mathrm{G}$ (general degree) $=0$; altered voice in a mild degree (MDG): $\mathrm{G}=1$; moderate vocal alteration (MODG): $\mathrm{G}=2$; and extreme vocal alteration
(EDG): $\mathrm{G}=3$. The parameter $\mathrm{G}$ was chosen because it represents the global impression that we have of the voices. The other parameters - roughness, breathiness, asthenia and strain - were used in the correlation with the other data. The acoustic analysis was performed with the program Praat, using the medial portion of the sustained emission, because it is more stable. The automatic measures of interest were extracted: fundamental frequency, jitter (perturbation measure related to the frequency of the voice), shimmer (perturbation measure related to the intensity of the voice), and harmonics-tonoise ratio. A qualitative analysis of the spectrographic tracing of the same emission was carried out using the program Spectrogram, version 16.0, which was chosen due to the quality of the definition of the spectrogram.

Aspects related to orofacial motricity, resonance and speech were observed and registered during the contact with the educators to record their voices.

The AVG, MDG, MODG and EDG groups were compared in relation to the minimum noise levels that were observed (adequate, altered) and to the other findings: vocal alteration degrees indicated in the educators' vocal self-assessment (adequate, mild, moderate or extreme); automatic acoustic measures and spectrographic analysis (adequate, altered); observed orofacial motricity, resonance and speech (adequate or altered).

The statistical program SPSS was utilized and the findings were analyzed by descriptive statistics and application of chi-square test. A level of significance of $10 \%$ was considered due to sample size.

The research was approved by the Ethics Committee of the institution (006/11). The institutions' principals and educators were informed about the project and signed a consent document.

\section{RESULTS}

The educators' age ranged between 21 and 56 years (mean of 30 years).

Approximately $25 \%$ of the educators presented adequate voice and $75 \%$, altered voice in the auditoryperceptual assessment of the voice by means of the GRBAS scale, considering the global degree of alteration $(\mathrm{G})$. Among the altered voices, $67 \%$ were classified as mild alteration and $33 \%$ as moderate alteration. None were classified as extreme vocal alteration; therefore, the EDG group was not constituted.

Of the alterations that were found, $86 \%$ of the voices were rough, $71 \%$ breathy, $14 \%$ asthenic and $24 \%$ strained; $67 \%$ were rough-breathy.

The mean noise level in the different spaces varied between $58.1 \mathrm{~dB}$ (discomfort 2, i.e., altered) and 83.7 
$\mathrm{dB}$ (considered damage 2, also altered). The general mean was $70.4 \mathrm{~dB}$ (damage 2). The maximum levels ranged between $58.7 \mathrm{~dB}$ and $100.5 \mathrm{~dB}$, with mean of $82.7 \mathrm{~dB}$; and the minimum levels between $37.8 \mathrm{~dB}$ and $70.6 \mathrm{~dB}$, mean of $56.1 \mathrm{~dB}$.

The educators' vocal self-assessment ranked an average of 5.1 on the visual analogue scale, being classified as moderate alteration.

Approximately half of the educators presented $\mathrm{f} 0$ values out of the expectation in the acoustic assessment, and the major part presented lower frequencies. The jitter values were altered for $32 \%$, the shimmer ones for $43 \%$ and the harmonics-to-noise ratio, for $64 \%$.

The majority of the aspects of the spectrographic tracing were altered with noise between the harmonics, irregularity and interrupted tracing, as well as alterations in the definition of the harmonics, reduced number of harmonics and low frequency concerning the definition limit. In addition, $57 \%$ of the educators presented alterations in orofacial motricity, resonance or speech, in isolation or in combination. Speech alterations were observed in $36 \%$, resonance alterations in $21 \%$ and orofacial motricity alterations, in $18 \%$. The following were observed with highest frequency: locked joint (24\%), hyponasal resonance (19\%), mouth breathing (19\%), open bite or crossbite (14\%) and frontal lisp (14\%).

Educators with mild or moderate vocal alteration were exposed to levels that were considered inadequate with higher frequency than the educators from the group without alteration (Table 1).

As for the vocal self-assessment, orofacial motricity/ resonance/speech and acoustic measures data, there was no difference among the groups, except for the jitter values, which were considered to be altered with higher frequency in the groups with vocal alteration (Table 1).

Altered tracing and substitution of harmonics for noise were observed with higher frequency in the groups of educators with vocal alteration (Table 2).

\section{DISCUSSION}

The vocal alterations were more prevalent in institutions with higher noise level.

High occurrence of alteration was observed in the vocal assessment performed with the GRBAS scale, in agreement with the literature review, ${ }^{24}$ although the methodological procedures have been varied.

Mild alterations predominated and no case of extreme alteration was found. Only extreme vocal alterations lead to absences or sick leaves, as, in the teachers' perception, mild or moderate dysphonias do not limit
Table 1. Comparison among the groups AVG, MDG and MODG in relation to noise levels, vocal self-assessment and acoustic measures. São Paulo, SP, 2009.

\begin{tabular}{|c|c|c|c|c|c|c|c|}
\hline \multirow[t]{2}{*}{ Variable } & \multicolumn{2}{|c|}{$\begin{array}{l}\text { AVG } \\
(n=7)\end{array}$} & \multicolumn{2}{|c|}{$\begin{array}{l}\text { MDG } \\
(n=14)\end{array}$} & \multicolumn{2}{|c|}{$\begin{array}{l}\text { MODG } \\
(n=7)\end{array}$} & \multirow[t]{2}{*}{$p$} \\
\hline & $\mathrm{n}$ & $\%$ & $\mathrm{n}$ & $\%$ & $\mathrm{n}$ & $\%$ & \\
\hline \multicolumn{8}{|l|}{ Noise level } \\
\hline Adequate & 6 & 86 & 7 & 50 & 1 & 14 & $0.045^{*}$ \\
\hline Altered & 1 & 14 & 7 & 50 & 6 & 86 & \\
\hline \multicolumn{8}{|c|}{ Vocal self-assessment } \\
\hline $\begin{array}{l}\text { Adequate } \\
\text { voice }\end{array}$ & 0 & 0 & 2 & 14 & 0 & 0 & 0.478 \\
\hline \multicolumn{8}{|l|}{ Altered voice } \\
\hline $\begin{array}{l}\text { Mild } \\
\text { degree }\end{array}$ & 4 & 57 & 4 & 29 & 2 & 29 & \\
\hline $\begin{array}{l}\text { Moderate } \\
\text { degree }\end{array}$ & 1 & 14 & 3 & 21 & 3 & 42 & \\
\hline $\begin{array}{l}\text { Extreme } \\
\text { degree }\end{array}$ & 2 & 29 & 5 & 36 & 2 & 29 & \\
\hline
\end{tabular}

Orofacial motricity, resonance and speech

$\begin{array}{llllllll}\text { Adequate } & 3 & 43 & 9 & 64 & 3 & 43 & 0.617 \\ \text { Altered } & 4 & 57 & 5 & 36 & 4 & 57 & \end{array}$

Acoustic measures

Fundamental frequency

$\begin{array}{llllllll}\text { Adequate } & 4 & 57 & 5 & 36 & 4 & 57 & 0.786 \\ \text { Altered } & 3 & 43 & 9 & 64 & 3 & 43 & \\ & & & & & & & \end{array}$

$\begin{array}{lccccccc}\text { Adequate } & 7 & 100 & 9 & 64 & 3 & 43 & 0.090^{*} \\ \text { Altered } & 0 & 0 & 5 & 36 & 4 & 57 & \\ \text { Shimmer } & & & & & & & \\ \text { Adequate } & 4 & 57 & 9 & 64 & 3 & 43 & 0.519 \\ \text { Altered } & 3 & 43 & 5 & 36 & 4 & 57 & \end{array}$

Harmonics-to-noise ratio

\begin{tabular}{llllllll} 
Adequate & 3 & 43 & 6 & 43 & 1 & 14 & 0.617 \\
Altered & 4 & 57 & 8 & 57 & 6 & 86 & \\
\hline
\end{tabular}

* Statistically signifi cant values $(p \leq 0.10)$, chi-square test AVG: group with adequate voice (G of the GRBAS scale $=0)$; MDG: group with mildly altered voice (G of the GRBAS scale $=1$ ); MODG: group with moderately altered voice $(G$ of the GRBAS scale $=2$ )

their daily work and are considered inherent in the profession. ${ }^{10,16}$ Rough-breathy voice was found in half of the educators, which may indicate presence of vocal fold nodules. ${ }^{1,19}$ Laryngeal assessment was not performed due to the professionals' difficulty in leaving the classroom. Roughness, breathiness and hyperfunction/strain have been prevalent in other studies, ${ }^{13,19}$ but only one ${ }^{19}$ found alterations related to phonotrauma by means of laryngeal assessment.

No association was observed between voice alteration in the speech pathologist assessment and the educators' 
Table 2. Comparison between the groups AVG, MDG and MODG in relation to the spectrographic analysis. São Paulo, SP. 2009

\begin{tabular}{|c|c|c|c|c|c|c|c|}
\hline \multirow{2}{*}{$\begin{array}{l}\text { Spectrographic } \\
\text { analysis }\end{array}$} & \multicolumn{2}{|c|}{$\begin{array}{l}\text { AVG } \\
(n=7)\end{array}$} & \multicolumn{2}{|c|}{$\begin{array}{c}\text { MDG } \\
(n=14)\end{array}$} & \multicolumn{2}{|c|}{$\begin{array}{c}\text { MODG } \\
(\mathrm{n}=7)\end{array}$} & \multirow[t]{2}{*}{$p$} \\
\hline & $\mathrm{n}$ & $\%$ & $\mathrm{n}$ & $\%$ & $\mathrm{n}$ & $\%$ & \\
\hline \multicolumn{8}{|l|}{ Tracing } \\
\hline Adequate & 1 & 14 & 0 & 0 & 0 & 0 & 0.078 \\
\hline Altered & 6 & 86 & 21 & 100 & 7 & 100 & \\
\hline \multicolumn{8}{|l|}{ Harmonics } \\
\hline Adequate & 1 & 14 & 5 & 36 & 1 & 14 & 0.482 \\
\hline Altered & 6 & 86 & 9 & 64 & 6 & 86 & \\
\hline \multicolumn{8}{|c|}{ Noise between harmonicss } \\
\hline Absent & 3 & 43 & 5 & 36 & 0 & 0 & 0.186 \\
\hline Present & 4 & 57 & 9 & 64 & 7 & 100 & \\
\hline \multicolumn{8}{|c|}{ Subst. harmonics for noise } \\
\hline Absent & 6 & 86 & 8 & 57 & 1 & 14 & $0.044^{*}$ \\
\hline Present & 1 & 14 & 6 & 43 & 6 & 86 & \\
\hline \multicolumn{8}{|c|}{ Graphic regularity } \\
\hline Present & 2 & 29 & 6 & 43 & 1 & 14 & 0.498 \\
\hline Absent & 5 & 71 & 8 & 57 & 6 & 86 & \\
\hline \multicolumn{8}{|l|}{ Interruptions } \\
\hline Absent & 2 & 29 & 2 & 14 & 2 & 29 & 0.576 \\
\hline Present & 5 & 71 & 12 & 86 & 5 & 71 & \\
\hline \multicolumn{8}{|l|}{ Bifurcations } \\
\hline Absent & 7 & 100 & 12 & 86 & 3 & 43 & 0.137 \\
\hline Present & 0 & 0 & 2 & 14 & 4 & 57 & \\
\hline \multicolumn{8}{|c|}{ Harmonics definition } \\
\hline Adequate & 1 & 14 & 1 & 7 & 0 & 0 & 0.617 \\
\hline Altered & 6 & 86 & 13 & 93 & 7 & 100 & \\
\hline
\end{tabular}

* Statistically significant values $(p \leq 0.10)$, chi-square test AVG: group with adequate voice (G of the GRBAS scale $=0$ ); MDG: group with mildly altered voice (G of the GRBAS scale $=1$ ); MODG: group with moderately altered voice ( $\mathrm{G}$ of the GRBAS scale $=2$ )

self-assessment. Educators with adequate voice in the speech pathology assessment evaluated themselves as altered, the majority with mild alteration. Those with mild alteration in the speech and audiology assessment considered themselves mainly with extreme vocal alteration and two evaluated themselves as normal. Educators with moderate alteration were distributed among selfreported mild, moderate or extreme alteration. Teachers usually have difficulty in perceiving their voices, ${ }^{16,19}$ but self-perception can be an important tool for the early detection of vocal problems and adherence to treatment, when indicated. The educators do not refer only to vocal quality in the self-assessment, but also to aspects like difficulty to speak loudly or in the presence of noise, ${ }^{17,19}$ which was reported by participants in this study.

The spectrographic analysis showed the professionals' difficulty to speak in the presence of noise: the analyzed aspects were altered in educators with adequate and altered voice, like harmonics definition, harmonics interruptions, noise between harmonics and graphic irregularity. These alterations are associated with little vocal brightness and projection, i.e., difficulties to speak in strong intensity, to make oneself be heard in large spaces and in the presence of competitive noise. Little projection and vocal modulation was observed in another study with teachers. ${ }^{17}$ The richer the harmonics series, the better the vocal quality and the glottal closure, ${ }^{1}$ conditions that facilitate vocal projection.

Altered spectrographic tracing and substitution of harmonics for noise were associated with vocal alteration. This indicates that global alterations of the spectrogram enabled to differentiate adequate voices from altered voices. Besides, the substitution of harmonics for noise is related to vocal fold nodules and glottal gap, ${ }^{1}$ whose main auditory correlate would be roughness or roughness with breathiness. The altered vocal quality that was the most found in this study was the rough-breathy one.

In this study, f0 was altered for more than half of the participants, who presented mainly f0 lower in the analysis of the acoustic measures of automatic extraction. This decrease can indicate difficulties in vocal extension or vocal fatigue in educators without alterations in the GRBAS scale; altered voice can be related to the presence of mass lesions in the vocal folds, ${ }^{1}$ which should be investigated in future studies. The vocal folds may become overloaded if the vocal extension is reduced.

The harmonics-to-noise ratio was altered for more than half of the educators and did not differentiate between altered and adequate voices, indicating that vocal extension limitations may generate fatigue, whose signs appear on the spectrum, but are not perceived in auditory terms. The shimmer values were adequate to the majority of the participants, like the jitter values, but the latter was able to differentiate the voices, reiterating that it correlates more directly with voice alterations than shimmer. ${ }^{1}$ Thus, the educators with altered voice presented more difficulty in controlling the vibration of the vocal folds than alterations in glottal resistance. ${ }^{1}$ Jitter is a measure of aperiodicity that loses reliability as the aperiodicity of the voice increases..$^{25}$ There were no voices with extreme alterations in this research.

Speech, resonance and orofacial motricity were altered, and the main alterations were locked joint or imprecise articulation, hyponasal resonance and mouth breathing, as well as bite alterations and presence of frontal lisp. These data are directly related to the vocal projection difficulties that were reported and observed in the spectrographic analysis, as well as to an intense overload of the vocal tract.

Imprecise articulation indicates difficulties to control 
the phono-articulatory dynamics and can favor hypertonic laryngeal patterns as an attempt to compensate for speech intelligibility problems. ${ }^{1}$ It is also associated with lack of coordination between breathing and speaking, an aspect that needs to be intact for an adequate professional use of the voice. Impaired intelligibility may interfere in the teaching-learning process, mainly if it occurs in sound competition situations. Articulatory imprecision is associated with the psychodynamics of lack of clear ideas and unwillingness to communicate. ${ }^{1}$

Altered resonance negatively affects the amplification of the harmonics and indicates a restriction for the modification of adjustments in the vocal tract, ${ }^{1}$ which will be made inadequately and with effort. The orofacial motricity alterations and breathing specially through the mouth can lead to phonation with compensatory effort, causing laryngeal hyperfunction. ${ }^{1}$ Furthermore, respiratory alterations negatively affect sleep quality and attention capacity. The lack of adequate rest can reduce the educators' concentration levels and hinder the adequate performance of their work. ${ }^{6}$

These speech, resonance and orofacial motricity alterations were observed in educators with adequate voice and in those with altered voice. To the latter, it may be one more overload, and there is the need of speech pathology, ENT and dental assessment and treatment.

After the recordings, the educators received a feedback on the most relevant aspects that were observed. The spectrogram obtained from their emission was utilized, as the use of images of the acoustic analysis enables a better understanding of the vocal problem. ${ }^{25}$ The educators agreed with the observations, mainly those concerning the difficulties in vocal projection and resonance alterations.

High noise levels were observed in the three institutions, like in other studies; ; ${ }^{311,13,21}$ therefore, they represent risk environments for the professionals' and children's health in many aspects, which need to be modified. High noise levels interfere in communication, and they also hinder attention and concentration, interfere in memory and contribute to the occurrence of stress and excessive fatigue. In addition, they expose the worker to factors that may trigger occupational accidents. ${ }^{5}$ Many teachers are able to perceive the noise and associate it with vocal alterations, with impacts even on voice-related quality of life..$^{10}$

The means of the minimum values found were used to analyze the noise in relation to the educators' voice. This is the only way in which there would be a group exposed to noise levels within what is considered adequate. An association between mildly or moderately altered voice and exposure to noise levels that are considered inadequate was observed, as is shown in the literature, which indicates that the changes in the activities of the muscles related to vocal production, in an attempt to overcome the noise, will possibly lead to vocal quality deterioration. ${ }^{3,4,9,10,15,16,23,24}$ Another study has found an association between high noise levels and vocal alteration in teachers of one out of three analyzed schools. ${ }^{13}$

The adhesion of all the invited educators shows interest and need of research in the voice area in this professional category. The lack of studies on the theme points to the need of research that aims at environmental characterization and the problems it may cause to professionals and students, and also at evaluating multidisciplinary actions of health promotion in the search of a better quality of life to those who are involved.

The way in which each individual adjusts his/her voice to speak in the presence of noise can be peculiar, ${ }^{12}$ which indicates the need of more studies.

Our data strengthen the need of multisector measures to reduce noise levels and to promote the adequate use of the voice at the workplace, aiming to improve the quality of life of these professionals and of the children. It is fundamental that measures that have a collective focus are developed; such measures should emphasize the improvement in the acoustic comfort, the awareness-raising of the educators in relation to its alterations and to the importance of the treatment, when indicated. Likewise, the need of complementary laryngeal assessment will be discussed with the institutions' managers so that it is possible to think of a more specific instrumentalization of these educators to the professional use of the voice. 


\section{REFERENCES}

1. Behlau M, Madazio G, Feijó D, Pontes P. Avaliação de voz. In: Behlau M, organizadora. Voz, o livro do especialista. Rio de Janeiro: Revinter; 2001 . p.85-180.

2. Behlau M, Zambon F, Guerrieri AC, Roy N. Panorama epidemiológico sobre a voz do professor no Brasil. Rev Soc Bras Fonoaudiol. 2009; (Supl):1511.

3. Bovo R, Galceran M, Petruccelli J, Hatzopoulos S. Vocal problems among teachers: evaluation of a preventive voice program. J Voice. 2007;21(6):705-22. DOI:10.1016/j.jvoice.2006.07.002

4. Chen SH, Chiang SC, Chung YM, Hsiao LC, Hsiao TY. Risk factors and effects of voice problems for teachers. J Voice. 2010;24(2):183-92. DOI:10.1016/j.jvoice.2008.07.008

5. Cordeiro R, Clemente APG, Diniz CS, Dias A. Exposição ao ruído ocupacional como fator de risco para acidentes de trabalho. Rev Saude Publica. 2005;39(3):461-6. DOI:10.1590/S0034-89102005000300018

6. Ferreira LP, Latorre MRDO, Giannini SPP, Ghirardi ACAM, Karmann DF, Silva EE, et al. Influence of abusive vocal habits, hydration, mastication, and sleep in the occurrence of vocal symptoms in teachers. J Voice. 2010;24(1):86-92. DOI:10.1016/j.jvoice.2008.06.001

7. Gillivan-Murphy P, Drinnan MJ, O'Dwyer TP, Ridha H, Carding P. The effectiveness of a voice treatment approach for teachers with self-reported voice problems. / Voice. 2006;20(3):423-31. DOI:10.1016/j.jvoice.2005.08.002

8. Hirano M. Clinical examination of voice. New York: Springer-Verlag; 1981.

9. Ilomäki I, Laukkanen AM, Leppänen K, Vilkman E. Effects of voice training and voice hygiene education on acoustic and perceptual speech parameters and self-reported vocal well-being in female teachers. Logop Phoniatr Vocol. 2008;33(2):83-92. DOI:10.1080/14015430701864822

10. Jardim R, Barreto SM, Assunção AA. Condições de trabalho, qualidade de vida e disfonia entre docentes. Cad Saude Publica. 2007;23(10):2439-61. DOI:10.1590/S0102-311X2007001000019

11. Libardi A, Gonçalves CGO, Vieira TPG, Silvério KCA, Rossi D, Penteado RZ. O ruído em sala de aula e a percepção dos professores de uma escola de ensino fundamental de Piracicaba. Disturb Comun. 2006;18(2):167-78.

12. Lindstrom F, Waye KP, Södersten M, McAllister A Ternström S. Observations of the relationship between noise exposure and preschool teacher voice usage in day-care center environments. J Voice. 2011;25(2):16672. DOI:10.1016/j.jvoice.2009.09.009

13. McAllister AM, Granqvist S, Sjölander P, Sundberg J. Child voice and noise: a pilot study of noise in day cares and the effects on 10 children's voice quality according to perceptual evaluation. J Voice. 2009;23(5):587-93. DOI:10.1016/j.jvoice.2007.10.017

14. Ogido R, Costa EA, Machado HC. Prevalência de sintomas auditivos e vestibulares em trabalhadores expostos a ruído ocupacional. Rev Saude Publica. 2009;43(2):377-80. DOI:10.1590/S0034-89102009000200021

15. Pasa G, Oates I, Dacakis G. The relative effectiveness of vocal hygiene training and vocal function exercises in preventing voice disorders in primary school teachers. Logop Phoniatr Vocol. 2007;32(3):128-40. DOI:10.1080/14015430701207774

16. Penteado RZ, Pereira IMTB. Qualidade de vida e saúde vocal de professores. Rev Saude Publica. 2007;41(2):236-43. DOI:10.1590/S0034-89102007000200010

17. Servilha EAM, Roccon PF. Relação entre voz e qualidade de vida em professores universitários. Rev CEFAC. 2009;11(3):440-8. DOI:10.1590/S1516-18462009005000029

18. Shield BM, Dockrell JE. The effects of environmental and classroom noise on the academic attainments of primary school children. J Acoust Soc Am. 2008;123 (1):133-44. DOI:10.1121/1.2812596

19. Silvério KCA, Gonçalves CGO, Penteado RZ, Vieira TPG, Libardi A, Rossi D. Ações em saúde vocal: proposta de melhoria do perfil vocal de professores. Pro-Fono R Atual Cient. 2008;20(3):177-82. DOI:10.1590/S0104-56872008000300007

20. Simões-Zenari M, Latorre MRDO. Changes in behavior associated to the use of voice after a speech therapy intervention with professionals of child day care centers. Pro-Fono R Atual Cient. 2008;20(1):61-6. DOI:10.1590/S0104-56872008000100011

21. Simões-Zenari M, Bitar ML, Pereira MB. Análise do ruído em instituições de educação infantil. Rev Soc Bras Fonoaudiol. 2009;(Supl):2860.

22. Sousa MNC, Fiorini AC, Guzman MB. Incômodo causado pelo ruído a uma população de bombeiros. Rev Soc Bras Fonoaudiol. 2009;14(4):508-14. DOI:10.1590/S1516-80342009000400014

23. Ueda KH, Santos LZ, Oliveira IB. 25 anos de cuidados com a voz profissional: avaliando ações. Rev CEFAC. 2008;10(4):557-65. DOI:10.1590/S1516-18462008000400016

24. Van Houtte E, Claeys S, Wuyts F, Van Lierde K. The impact of voice disorders among teachers: vocal complaints, treatment-seeking behavior, knowledge of vocal care, and voice-related absenteeism. / Voice. 2011;25(5):570-5. DOI:10.1016/j.jvoice.2010.04.008

25. Vieira MN, Rosa LLC. Avaliação acústica na prática fonoaudiológica. In: Pinho SMR, Tsuji DH, Bohadana SC, organizadoras. Fundamentos em laringologia e voz. Rio de Janeiro: Revinter; 2006. p.33-52. 